\title{
Variation in the Use of Active Surveillance for Low-Risk Prostate Cancer Across US Census Regions
}

\author{
Bashir Al Hussein Al Awamlh ${ }^{1}$, Neal Patel ${ }^{1}$, Xiaoyue Ma $^{2}$, Adam Calaway ${ }^{3,4}$, Lee Ponsky ${ }^{3,4}$, \\ $\operatorname{Jim}$ C. $H u^{1}$ and Jonathan E. Shoag ${ }^{1,3,4 *}$ \\ ${ }^{1}$ Department of Urology, Weill Cornell Medicine, New York Presbyterian Hospital, New York, NY, United States, ${ }^{2}$ Division of \\ Biostatistics and Epidemiology, Department of Healthcare Policy and Research, Weill Cornell Medicine, New York, NY, \\ United States, ${ }^{3}$ Urology Institute, University Hospitals Cleveland Medical Center, Cleveland, OH, United States, ${ }^{4}$ Department \\ of Urology, Case Western Reserve University School of Medicine, Cleveland, OH, United States
}

OPEN ACCESS

Edited by:

Brian Rini,

Vanderbilt University, United States

Reviewed by:

Daniel E. Spratt,

University of Michigan, United States

Atreya Dash,

University of Washington

United States

${ }^{*}$ Correspondence:

Jonathan E. Shoag

jonathan.shoag@uhhospitals.org

Specialty section:

This article was submitted to

Genitourinary Oncology,

a section of the journal

Frontiers in Oncology

Received: 22 December 2020

Accepted: 24 February 2021

Published: 19 May 2021

Citation:

Al Hussein Al Awamlh B, Patel N, Ma X, Calaway A, Ponsky L, Hu JC and Shoag JE (2021) Variation in the

Use of Active Surveillance for

Low-Risk Prostate Cancer Across US

Census Regions.

Front. Oncol. 11:644885.

doi: 10.3389/fonc. 2021.644885
Substantial geographic variation in healthcare practices exist. Active surveillance (AS) has emerged as a critical tool in the management of men with low-risk prostate cancer. Whether there have been regional differences in adoption is largely unknown. The SEER "Prostate with Watchful Waiting Database" was used to identify patients diagnosed with localized low-risk prostate cancer and managed with AS across US census regions between 2010 and 2016. Multivariable logistic regression models were used to determine the impact of region on undergoing AS and factors associated with AS use within each US census region. Between 2010 and 2016, the proportion of men managed with AS increased from $20.8 \%$ to $55.9 \%$ in the West, $11.5 \%$ to $50.0 \%$ in Northeast, $9.9 \%$ to $43.4 \%$ in the South and $15.1 \%$ to $56.2 \%$ in Midwest $(p<0.0001)$. On multivariable analysis, as compared to the West, men in all regions were less likely to undergo AS ( $p$ < 0.001). Black men in the West (OR 1.36, 95\% Cl 1.25-1.49) and Midwest (OR $1.62,95 \% \mathrm{Cl} 1.35-1.95)$ were more likely to undergo AS, but less likely in Northeast (OR $0.80,95 \% \mathrm{Cl}$ 0.69-0.92). Men with higher socioeconomic status (SES) were more likely to undergo AS in the West (OR 1.47, 95\% Cl 1.39-1.55), Northeast (OR 1.57, 95\% Cl 1.36-1.81), and South (OR 1.24, 95\% Cl 1.13-1.37) but not in the Midwest (OR 0.85, $95 \% \mathrm{Cl}$ 0.73-0.98). We found striking regional differences in the uptake of AS according to race and SES. Geography must be taken into consideration when assessing barriers to AS use.

Keywords: low-risk prostate cancer, active surveillance, geographic variation, watchful waiting, radical prostatectomy, radiation therapy

\section{INTRODUCTION}

Active surveillance (AS) has been widely adopted for low-risk prostate cancer in an effort to mitigate the harms of overtreatment (1). Recent data has demonstrated an increase in AS use in the US from 15 to $42 \%$ between 2010 and 2015 (2). While this increase is encouraging, the US lags behind other countries which have adopted AS more robustly such as Sweden where $74 \%$ of men with low-risk prostate cancer were managed in this fashion during the same timeframe (3).

Geographic variation in healthcare delivery has been implicated as a source of idiosyncratic variation in healthcare utilization, outcomes, and spending for over 50 years $(4,5)$. Prostate cancer care has been shown to vary dramatically at the regional, county and facility levels, and even within the same practice (6-8). 
Recently, we demonstrated that when accounting for geographic variation, Black men were more likely than white men to undergo AS (9). These data highlight the importance of determining how men with low-risk prostate cancer are managed differently according to region. Here, we sought to elucidate regional differences, and contributors to AS use in men with low-risk prostate cancer across census regions in the US using nationally representative data.

\section{METHODS}

The SEER "Prostate with Watchful Waiting Database" was used to identify patients diagnosed with localized low-risk (clinical T1c-T2a, Gleason score $3+3$ and PSA $<10 \mathrm{ng} / \mathrm{mL}$ ) prostate cancer between 2010 and 2016. SEER collects and publishes cancer incidence, prevalence, and survival data from population-based cancer registries, that are nationally representative, covering approximately one third of the U.S. population. The "Prostate with Watchful Waiting Database," is a specialized database that contains active surveillance (or watchful waiting) information collected by SEER for prostate cancer cases diagnosed from 2010 to 2016 (10). Men with missing clinical data, including those whose initial management was unknown, and those that were not treated by their physicians for reasons such as the presence of comorbidities were excluded from analysis. This study was approved the Institutional Review Board at Weill Cornell Medicine and the SEER custom data group.

Subjects were categorized into one of four US census regions (Northeast, West, South, and Midwest) according to the location of the SEER registry reported. Clinical demographic factors were compared among men undergoing AS and definitive

TABLE 1 | Characteristics of men with low-risk prostate cancer in each US census region between 2010 and 2016.

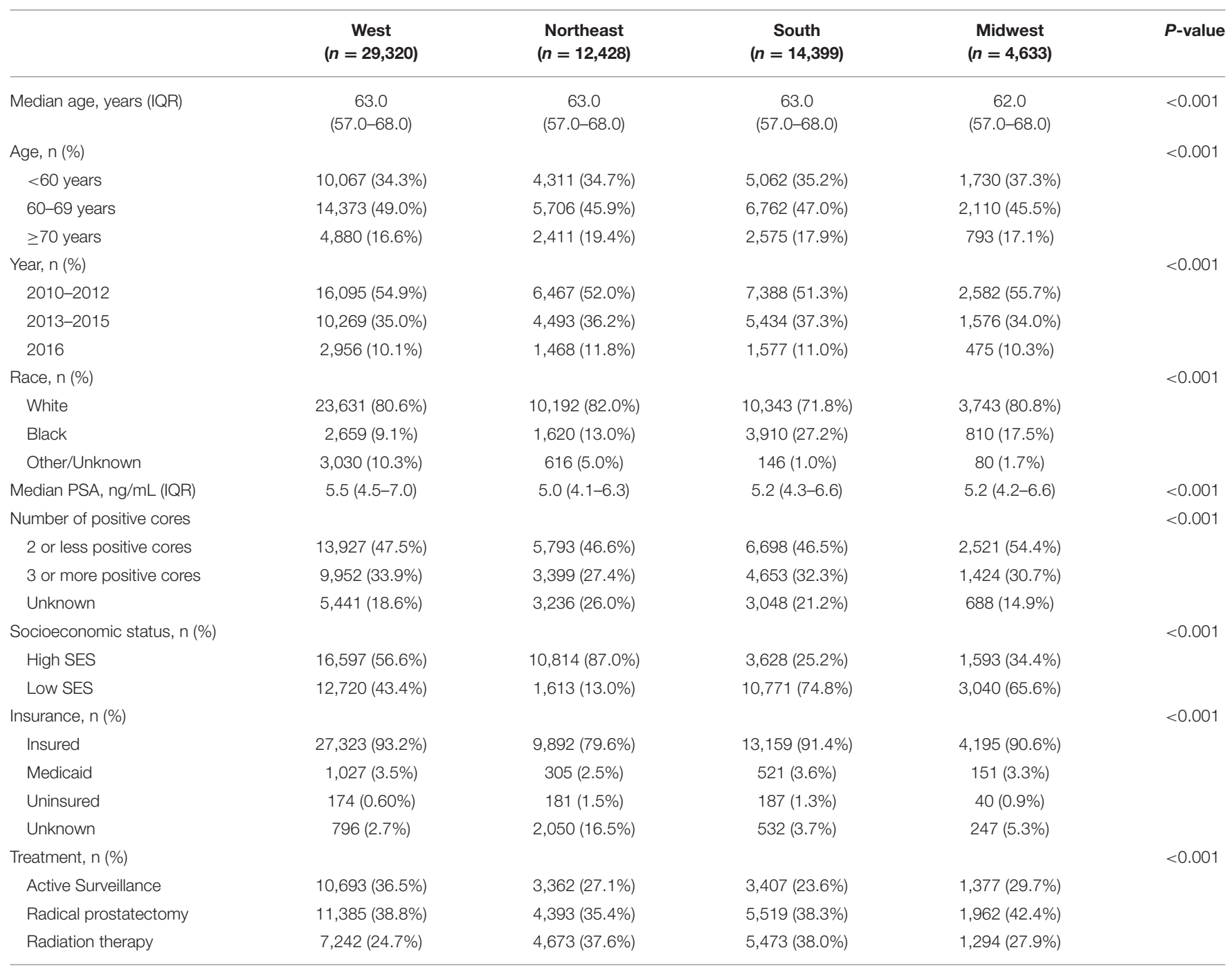


treatment (radical prostatectomy or radiation therapy). Clinical variables included age at the time of diagnosis, prostate specific antigen (PSA) level, and total and positive numbers of prostate biopsy cores. Demographic variables included insurance status (insured, Medicaid, uninsured, unknown), race (White, Black, and other/unknown) and socioeconomic status (SES) which was measured using the Yost index (composite score based on census tract-level median household income, median house value, median rent, percent below $150 \%$ of poverty line, education Index, percent working class, and percent unemployed) (11).

The main outcomes of the study were to determine how men were managed across different regions in the US between 2010 and 2016, and how clinical and demographic factors were associated with undergoing AS within each region. Clinical and demographic factors were compared using the chi-square test, $t$-test or Mann-Whitney test as indicated. Temporal trends were compared using the Cochran-Armitage trend test. Multivariable logistic regression was used to determine the impact of region on undergoing AS and in a separate analysis the cohort was stratified according to age. Multivariable models were also used to identify factors associated with AS use within each US census region. Statistical analyses were performed using $\mathrm{R}$ version 3.4.4 and SAS Version 9.4. All pvalues are two-sided with statistical significance evaluated at $\alpha=0.05$.

\section{RESULTS}

Characteristics of men diagnosed with low-risk prostate cancer are shown in Table 1. Black men constituted $27.2 \%$ of men diagnosed with low-risk prostate cancer in the South, $13.0 \%$ in the Northeast, $17.5 \%$ in the Midwest and $9.1 \%$ in the West $(p<$ 0.001). Among men diagnosed with low-risk prostate cancer, a higher proportion were of higher SES in the Northeast at $87.0 \%$ and the West at $56.6 \%$ as compared to the Midwest at $34.4 \%$ in and the South at 25.2\% ( $p<0.001)$. Between 2010 and 2016, the majority of men with low-risk prostate cancer were managed with radical prostatectomy in the West and Midwest at 38.8 and $42.2 \%$, respectively. Whereas, in the Northeast the majority of men were managed with radiation therapy at $37.6 \%$ and in the South men were managed almost equally with radiation therapy at $38.0 \%$ and radical prostatectomy at $38.3 \%(p<0.001)$.

The proportion of men managed with AS increased from 20.8 to $55.9 \%$ in the West, $11.5-50.0 \%$ in Northeast, 9.9$43.4 \%$ in the South and $15.1-56.2 \%$ in Midwest $(p<0.001$ trend test, Figure 1). The differences in characteristics in men undergoing AS by region are shown in Table 2 and by race in Supplementary Table 1.

On multivariable regression including US census regions, men in the South [adjusted odds ratio [aOR] 0.51, 95\% confidence interval [CI] 0.49-0.54], Northeast (aOR 0.50, 95\%CI $0.48-0.53$ ), and Midwest (aOR 0.71, 95\% CI 0.66-0.76) were
A

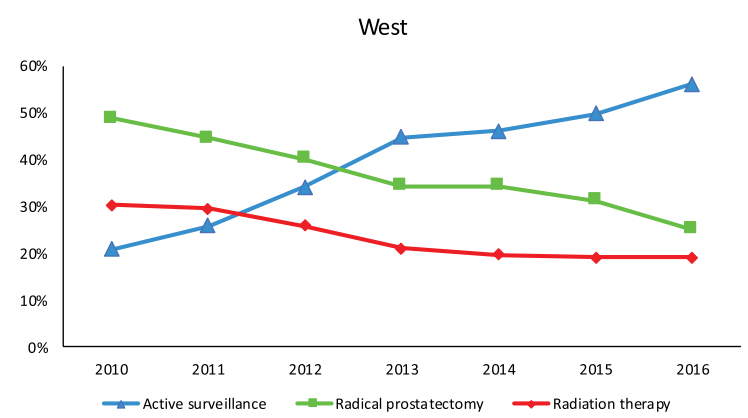

C

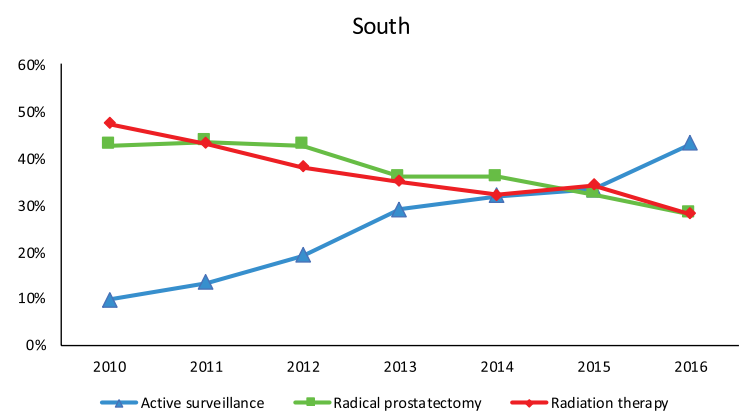

B

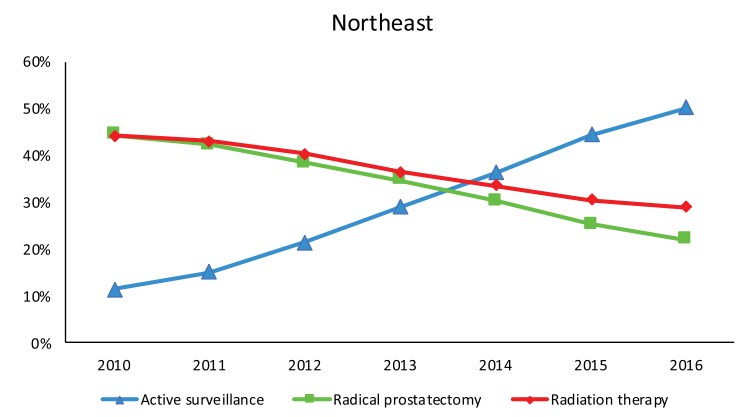

D

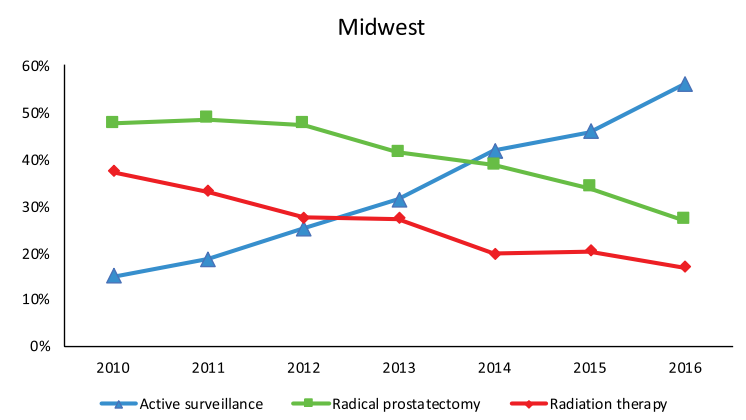

FIGURE 1 | Management of men with low-risk prostate cancer in each US census region between 2010 and 2016. (A) West (B) Northeast (C) South and (D) Midwest. 
TABLE 2 | Characteristics of men managed with active surveillance in each US census region between 2010 and 2016.

\begin{tabular}{|c|c|c|c|c|c|}
\hline & $\begin{array}{c}\text { West } \\
(n=10,693)\end{array}$ & $\begin{array}{l}\text { Northeast } \\
(n=3,362)\end{array}$ & $\begin{array}{c}\text { South } \\
(n=3,407)\end{array}$ & $\begin{array}{c}\text { Midwest } \\
(n=1,377)\end{array}$ & $P$-value \\
\hline Median age, years (IQR) & $64(59.0-68.0)$ & 65 (59.0-69.0) & $65.0(60.0-70.0)$ & $65.0(59.0-69.0)$ & $<0.001$ \\
\hline \multicolumn{6}{|l|}{ Age, n (\%) } \\
\hline$<60$ years & $3,060(28.6 \%)$ & $917(27.3 \%)$ & 819 (24.0\%) & 366 (26.6\%) & \\
\hline $60-69$ years & $5,522(51.6 \%)$ & $1,618(48.1 \%)$ & $1,653(48.5 \%)$ & 675 (49.0\%) & \\
\hline$\geq 70$ years & $2,111(19.7 \%)$ & $827(24.6 \%)$ & 935 (27.4\%) & $336(24.4 \%)$ & \\
\hline Year, n (\%) & & & & & $<0.001$ \\
\hline 2010-2012 & $4,253(39.8 \%)$ & $1,002(29.8 \%)$ & $1,022(30.0 \%)$ & 491 (35.7\%) & \\
\hline 2013-2015 & $4,787(44.8 \%)$ & $1,626(48.4 \%)$ & $1,700(48.9 \%)$ & 619 (45.0\%) & \\
\hline 2016 & $1,653(15.5 \%)$ & 734 (21.8\%) & 685 (20.1\%) & 267 (19.4\%) & \\
\hline Race, n (\%) & & & & & $<0.001$ \\
\hline White & 8,435 (78.9\%) & $2,814(83.7 \%)$ & $2,463(72.3 \%)$ & $1,061(77.1 \%)$ & \\
\hline Black & $1,028(9.6 \%)$ & 352 (10.5\%) & 890 (26.1\%) & 285 (20.7\%) & \\
\hline Other/Unknown & $1,028(11.5 \%)$ & 196 (5.8\%) & $54(1.6 \%)$ & $31(2.3 \%)$ & \\
\hline Median PSA, ng/mL (IQR) & $5.60(4.6-7.0)$ & $5.1(4.2-6.5)$ & $5.4(4.4-6.7)$ & $5.3(4.4-6.8)$ & $<0.001$ \\
\hline Number of positive cores, n (\%) & & & & & $<0.001$ \\
\hline 2 or less positive cores & $6,936(64.9 \%)$ & $2,236(66.5 \%)$ & $2,262(66.4 \%)$ & 994 (72.3\%) & \\
\hline 3 or more positive cores & $2,436(22.8 \%)$ & $580(17.3 \%)$ & $624(18.3 \%)$ & $258(18.7 \%)$ & \\
\hline Unknown & $1,321(12.4 \%)$ & $546(16.2 \%)$ & $521(15.3 \%)$ & 125 (9.1\%) & \\
\hline Socioeconomic status, n (\%) & & & & & $<0.001$ \\
\hline High SES & 6,664 (62.3\%) & $3,042(90.5 \%)$ & 957 (28.1\%) & 436 (31.7\%) & \\
\hline LOW SES & $4,029(37.7 \%)$ & $319(9.5 \%)$ & $2,450(71.9 \%)$ & $941(68.3 \%)$ & \\
\hline Insurance, n (\%) & & & & & $<0.001$ \\
\hline Insured & 9,878 (92.4\%) & $2,744(81.6 \%)$ & 3,098 (90.9\%) & $1,170(85.0 \%)$ & \\
\hline Medicaid & $320(3.0 \%)$ & 107 (3.2\%) & $91(2.7 \%)$ & 53 (3.9\%) & \\
\hline Uninsured & $60(0.6 \%)$ & $97(2.9 \%)$ & $48(1.4 \%)$ & $12(0.9 \%)$ & \\
\hline Unknown & $435(4.1 \%)$ & $414(12.3 \%)$ & $170(5.0 \%)$ & $142(10.3 \%)$ & \\
\hline
\end{tabular}

$I Q R$, Interquartile range.

Percentages may not add up $100 \%$ due to rounding.

less likely to undergo AS as compared to men in the West. Furthermore, on multivariable analysis that is stratified by age group (Supplementary Table 2), similar associations between clinical and sociodemographic factors, and the receipt of AS were noted across different ages. In region specific models, Black men in the West (aOR 1.36, 95\%CI 1.25-1.49) and Midwest (aOR 1.62, 95\%CI 1.35-1.95) were more likely to undergo AS than White men, but were less likely to undergo AS in the Northeast (aOR 0.80, 95\%CI 0.69-0.92) as compared to White men (Table 3). Men with higher SES were more likely to undergo AS in the West (aOR 1.47, 95\%CI 1.39-1.55), Northeast (aOR 1.57, 95\%CI 1.36-1.81), and South (aOR 1.24, 95\%CI 1.131.37) but not in the Midwest (aOR 0.85, 95\%CI 0.73-0.98). Multivariable models including an interaction term for race and SES (Supplementary Table 3) showed significant interactions between race and SES in all regions except the Midwest.

\section{DISCUSSION}

Here, we demonstrate that by 2016, the West and Midwest had the highest rate of AS use among men with low-risk prostate cancer in the US at 56\%. Whereas, the South was lagging behind other regions at $43 \%$. We also found that clinical factors such as patient age, number of biopsies, and PSA level were associated with undergoing AS irrespective of US census region, while the contribution of demographic factors, such as SES, race, and patient insurance, to surveillance use varied across regions.

Recently, Loeb et al. (12) demonstrated in patients in an integrated health system, there are differences in the management of low-risk prostate cancer according to geography among US veterans. Similar to our data, the authors found that the use of AS was highest in the West and lowest in the Northeast. Factors explaining geographic variations in care are likely multifactorial and complex, and include availability of resources, treating physician specialty (urologist vs. radiation oncologist) (6), and individual patient and clinician preferences (7). Moreover, in a similar study that linked SEER AS data to county area data, the authors used different statistical analyses and also found that AS independently varied across different regions in the US (13). Our results underscore that regional variation in low-risk prostate cancer care may be driven by differential weighting of demographic factors across regions. The different associations observed among these factors in relation to the use of AS within each region are impressive, and highlight the need to 
TABLE 3 | Multivariable logistic regression analysis assessing receipt of active surveillance.

\begin{tabular}{|c|c|c|c|c|}
\hline & West & Northeast & South & Midwest \\
\hline Region* & Reference & $0.50(0.48-0.53)$ & $0.51(0.49-0.54)$ & $0.71(0.66-0.76)$ \\
\hline Age (per one year) & $1.04(1.03-1.04)$ & $1.04(1.03-1.05)$ & $1.06(1.06-1.07)$ & $1.06(1.05-1.07)$ \\
\hline \multicolumn{5}{|l|}{ Year } \\
\hline 2010-2012 & Reference & Reference & Reference & Reference \\
\hline 2013-2015 & $2.58(2.44-2.73)$ & $3.21(2.91-3.53)$ & 3.06 (2.79-3.35) & $3.04(2.61-3.54)$ \\
\hline 2016 & 3.79 (3.48-4.13) & $5.90(5.17-6.73)$ & $5.25(4.62-5.97)$ & $6.19(4.94-7.76)$ \\
\hline \multicolumn{5}{|l|}{ Race } \\
\hline White & Reference & Reference & Reference & Reference \\
\hline Black & $1.36(1.25-1.49)$ & $0.80(0.69-0.92)$ & $1.08(0.98-1.19)$ & $1.62(1.35-1.95)$ \\
\hline Other/Unknown & $1.09(1.00-1.19)$ & $1.20(0.99-1.45)$ & $1.78(1.22-2.60)$ & $1.27(0.77-2.11)$ \\
\hline PSA (per 1 ng/mL) & $0.98(0.97-0.99)$ & 1.01 (0.99-1.03) & $0.97(0.95-0.99)$ & $1.00(0.96-1.03)$ \\
\hline \multicolumn{5}{|l|}{ Number of positive cores } \\
\hline 3 or more positive cores & Reference & Reference & Reference & Reference \\
\hline 2 or less positive cores & 3.33 (3.14-3.53) & $3.41(3.05-3.81)$ & $3.64(3.28-4.04)$ & $3.44(2.90-4.07)$ \\
\hline Unknown & $1.20(1.11-1.30)$ & $1.50(1.31-1.73)$ & $1.67(1.46-1.91)$ & $1.35(1.04-1.74)$ \\
\hline \multicolumn{5}{|l|}{ Socioeconomic status } \\
\hline Low SES & Reference & Reference & Reference & Reference \\
\hline High SES & $1.47(1.39-1.55)$ & $1.57(1.36-1.81)$ & $1.24(1.13-1.37)$ & 0.85 (0.73-0.98) \\
\hline \multicolumn{5}{|l|}{ Insurance } \\
\hline Insured & Reference & Reference & Reference & Reference \\
\hline Medicaid & $0.76(0.66-0.88)$ & $1.26(0.97-1.64)$ & $0.79(0.61-1.01)$ & $1.22(0.84-1.79)$ \\
\hline Uninsured & $1.16(0.83-1.63)$ & 4.17 (3.01-5.78) & $1.48(1.03-2.12)$ & $1.29(0.62-2.72)$ \\
\hline Unknown & $1.67(1.43-1.95)$ & $0.59(0.52-0.67)$ & $1.26(1.03-1.55)$ & $3.18(2.37-4.26)$ \\
\hline
\end{tabular}

*separate multivariable logistic regression analysis assessing receipt of active surveillance in the overall cohort including region as a variable.

understand and mitigate racial and SES barriers to AS within each region.

The observed geographic variation in the use of AS is impressive, but similar trends in the adoption of new treatment modalities have been previously seen in other malignancies. For instance, in the 1980's the use of breast-conserving surgery, which may serve as a model for studying the adoption new treatments, was shown to substantially vary in different regions in the US following its initial recommendation by experts (14). Similarly, by 2010 half of the colon resections performed in the US were laparoscopic, however, wide geographic variation in the use of laparoscopic colectomy for colon cancer persisted at that time ranging from 0 to $69 \%$ (15). Such trends in other cancer treatments also suggest that treatment location may considerably influence a patient's options for treatment approach and unequal access to new treatments is expected when a new treatment is first adopted.

Current AS guidelines do not recommend differential treatment of Black men, but suggest discussing the implications of potentially harboring higher-grade tumors when enrolling Black men into AS protocols (16). Here, we found that Black men undergo treatment differently in different regions of the US, independent of SES and other clinical factors. If a Black man is diagnosed with low-risk prostate cancer in the West or Midwest, he is more likely to be managed with AS. However, if he receives care in the Northeast, he is less likely to undergo AS than his White counterparts. This variation in care for
Black men, compared to White men, in different regions maybe partly resultant from uncertainty in the management of Black men with low-risk cancer and the heterogeneity among Black men community in the US in different regions (17). These results further emphasize the importance of considering geography when assessing racial disparities in prostate cancer care (9).

Similar to previous studies, we also found that a higher SES is associated with undergoing AS (18). The difference in care according to SES is more pronounced in the Northeast and West. Interestingly, SES has no impact on the choice of treatment in the Midwest. These differences according to SES seen in other regions are perhaps related to access to academic or tertiary centers that are more likely to provide guideline concordant care (AS) (8). Alternatively, lower SES may be associated with the inability to follow up with the AS protocol, thus receiving upfront definitive treatment (19). Of note, while we observed significant differences based on insurance status, it is difficult to interpret these associations given that they occurred in men with unknown insurance.

This study has several limitations. First, it is a retrospective analysis subject to the limitations associated with data collection (20). Second, we could not determine the difference between AS or watchful waiting, and we were not able to deduce that based on frequency of testing with PSA or prostate biopsies after initial enrollment, as these data are not available. However, 
the median age of men on AS was 65, which is consistent with AS rather than watchful waiting given the life expectancy. Population-based studies have shown that only a small number of men (up to one third) on AS adhere to AS protocols, suggesting that differentiating AS from WW in a community setting beyond initial intent of treatment is challenging $(21,22)$. It is worth noting here that AS studies found Black men to be monitored less intensely than white men and were more likely to be lost to follow up $(23,24)$. We found that Black men on AS have significantly lower SES compared to others, therefore, it is plausible that the data overestimated Black men undergoing AS as opposed to watchful waiting. Third, we were not able to determine who undergoes definitive treatment after initially being managed with AS. Finally, and perhaps most importantly, unlike other studies that use data on smaller geographic areas that is more detailed (7), we were limited by the geographic information available to us and study with more granular geographic information may have benefits. This also precluded a more detailed analyses of regional factors (rather than patient factors) that contributed to such variability, such as treating facility, average regional distances traveled to receive care, or number of physicians or robots in the region. These limitations notwithstanding, these data are nationally representative and demonstrate substantial variations in the association of demographic factors in care across the US for low-risk prostate cancer. This study provides opportunities for policy makers and professional societies to study and better understand how to limit the unwarranted role of demographic factors in the use of AS and reduce variation in the guideline recommended care.

In conclusion, We found an increase in uptake of AS across all regional in the US between 2010 and 2016. Men in the West are more likely to managed with AS compared to other regions. Moreover, there are striking regional differences in the uptake of AS according to race and SES. Further study is needed to better understand these geographic variations in care in order to hone in efforts to eliminate the demographic barriers to AS.

\section{REFERENCES}

1. Chen RC, Rumble RB, Loblaw DA, Finelli A, Ehdaie B, Cooperberg MR, et al. Active surveillance for the management of localized prostate cancer (Cancer Care Ontario Guideline): American Society of Clinical Oncology clinical practice guideline endorsement. J Clin Oncol. (2016) 34:2182-90. doi: 10.1200/JCO.2015. 65.7759

2. Mahal BA, Butler S, Franco I, Spratt DE, Rebbeck TR, D'Amico AV, et al. Use of active surveillance or watchful waiting for low-risk prostate cancer and management trends across risk groups in the United States, 2010-2015. JAMA. (2019) 321:704-6. doi: 10.1001/jama.2018.19941

3. Loeb S, Folkvaljon Y, Curnyn C, Robinson D, Bratt O, Stattin P. Uptake of active surveillance for very-low-risk prostate cancer in Sweden. JAMA Oncol. (2017) 3:1393-8. doi: 10.1001/jamaoncol.2016. 3600

4. Wennberg J, Gittelsohn A. Small area variations in health care delivery: a population-based health information system can guide planning and regulatory decision-making. Science. (1973) 182:1102-8. doi: 10.1126/science.182.4117.1102

\section{DATA AVAILABILITY STATEMENT}

The data analyzed in this study is subject to the following licenses/restrictions: The Surveillance, Epidemiology and End Results (SEER)-Medicare-linked database combines clinical information from population-based cancer registries with claims information from the Medicare program. The dataset has to be applied. Requests to access these datasets should be directed to https://healthcaredelivery.cancer.gov/seermedicare/ contact.html.

\section{ETHICS STATEMENT}

The studies involving human participants were reviewed and approved by Weill Conrell Medicine institutional review Board. Written informed consent for participation was not required for this study in accordance with the national legislation and the institutional requirements.

\section{AUTHOR CONTRIBUTIONS}

BA, NP, XM, and JS analyzed the data and drafted the manuscript. $\mathrm{AC}$ and LP helped interpreted the data. BA, JH, and JS designed the study. All authors contributed to the article and approved the submitted version.

\section{FUNDING}

JS and JH were supported by The Frederick J. and Theresa Dow Wallace Fund of the New York Community Trust. JS was supported by the Damon Runyon Cancer Research Foundation Physician Scientist Training Award.

\section{SUPPLEMENTARY MATERIAL}

The Supplementary Material for this article can be found online at: https://www.frontiersin.org/articles/10.3389/fonc. 2021.644885/full\#supplementary-material

5. Wennberg JE, Fisher ES, Goodman DC, Skinner JS. Tracking the Care of Patients With Severe Chronic Illness-The Dartmouth Atlas of Health Care 2008. Lebanon: The Dartmouth Institute for Health Policy and Clinical Practice (2008).

6. Hoffman KE, Niu J, Shen Y, Jiang J, Davis JW, Kim J, et al. Physician variation in management of low-risk prostate cancer: a population-based cohort study. JAMA Intern Med. (2014) 174:1450-9. doi: 10.1001/jamainternmed.2014.3021

7. Auffenberg GB, Lane BR, Linsell S, Cher ML, Miller DC. Practice- vs physician-level variation in use of active surveillance for men with low-risk prostate cancer: implications for collaborative quality improvement. JAMA Surg. (2017) 152:978-80. doi: 10.1001/jamasurg.2017.1586

8. Löppenberg B, Friedlander DF, Krasnova A, Tam A, Leow JJ, Nguyen PL, et al. Variation in the use of active surveillance for low-risk prostate cancer. Cancer. (2018) 124:55-64. doi: 10.1002/cncr.30983

9. Al Hussein Al Awamlh B, Ma X, Christos P, Hu JC, Shoag JE. Active surveillance for black men with low-risk prostate cancer in the United States. N Engl J Med. (2019) 381:2581-2. doi: 10.1056/NEJMc1912868

10. Prostate With Watchful Waiting Database - SEER Data \& Software. Available online at: https://seer.cancer.gov/seerstat/databases/prostate-ww/index.html (accessed February 21, 2019). 
11. Yost K, Perkins C, Cohen R, Morris C, Wright W. Socioeconomic status and breast cancer incidence in California for different race/ethnic groups. Cancer Causes Control. (2001) 12:703-11. doi: 10.1023/a:10112400 19516

12. Loeb S, Byrne NK, Wang B, Makarov DV, Becker D, Wise DR, et al. Exploring variation in the use of conservative management for low-risk prostate cancer in the veterans affairs healthcare system. Eur Urol. (2020) 77:683-6. doi: 10.1016/j.eururo.2020.02.004

13. Washington SL, Jeong CW, Lonergan PE, Herlemann A, Gomez SL, Carroll PR, et al. Regional variation in active surveillance for lowrisk prostate cancer in the US. JAMA Netw Open. (2020) 3:e2031349. doi: 10.1001/jamanetworkopen.2020.31349

14. Nattinger AB, Gottlieb MS, Veum J, Yahnke D, Goodwin JS. Geographic variation in the use of breast-conserving treatment for breast cancer. $N$ Engl J Med. (1992) 326:1102-7. doi: 10.1056/NEJM199204233261702

15. Reames BN, Sheetz KH, Waits SA, Dimick JB, Regenbogen SE. Geographic variation in use of laparoscopic colectomy for colon cancer. J Clin Oncol. (2014) 32:3667-72. doi: 10.1200/JCO.2014.57.1588

16. Carroll PH, Mohler JL. NCCN guidelines updates: prostate cancer and prostate cancer early detection. J Natl Compr Canc Netw. (2018) 16:620-3. doi: 10.6004/jnccn.2018.0036

17. Knight SJ, Siston AK, Chmiel JS, Slimack N, Elstein AS, Chapman GB, et al. Ethnic variation in localized prostate cancer: a pilot study of preferences, optimism, and quality of life among black and white veterans. Clin Prostate Cancer. (2004) 3:31-7. doi: 10.3816/CGC.2004.n.010

18. Butler SS, Loeb S, Cole AP, Zaslowe-Dude C, Muralidhar V, Kim DW, et al. United States trends in active surveillance or watchful waiting across patient socioeconomic status from 2010 to 2015. Prostate Cancer Prostatic Dis. (2020) 23:179-83. doi: 10.1038/s41391-019-0175-9

19. Andrulis DP. Access to care is the centerpiece in the elimination of socioeconomic disparities in health. Ann Intern Med. (1998) 129:412-6. doi: 10.7326/0003-4819-129-5-199809010-00012
20. Jeong CW, Washington SL, Herlemann A, Gomez SL, Carroll PR, Cooperberg MR. The new surveillance, epidemiology, and end results prostate with watchful waiting database: opportunities and limitations. Eur Urol. (2020) 78:335-44. doi: 10.1016/j.eururo.2020.01.009

21. Loeb S, Walter D, Curnyn C, Gold HT, Lepor H, Makarov DV. How active is active surveillance? Intensity of followup during active surveillance for prostate cancer in the United States. J Urol. (2016) 196:721-6. doi: 10.1016/j.juro.2016.02.2963

22. Peterson S, Basak R, Moon DH, Liang C, Basak RS, Walden S, et al. Population-based cohort of prostate cancer patients on active surveillance (AS): guideline adherence, conversion to treatment and decisional regret. J Clin Oncol. (2019) 37:6512. doi: 10.1200/JCO.2019.37.15_sup pl.6512

23. Krishna S, Fan Y, Jarosek S, Adejoro O, Chamie K, Konety B. Racial disparities in active surveillance for prostate cancer. J Urol. (2017) 197:342-9. doi: 10.1016/j.juro.2016.08.104

24. Ginsburg KB, Auffenberg GB, Qi J, Powell IJ, Linsell SM, Montie JE, et al. Risk of becoming lost to follow-up during active surveillance for prostate cancer. Eur Urol. (2018) 74:704-7. doi: 10.1016/j.eururo.2018. 08.010

Conflict of Interest: The authors declare that the research was conducted in the absence of any commercial or financial relationships that could be construed as a potential conflict of interest.

Copyright (C) 2021 Al Hussein Al Awamlh, Patel, Ma, Calaway, Ponsky, Hu and Shoag. This is an open-access article distributed under the terms of the Creative Commons Attribution License (CC BY). The use, distribution or reproduction in other forums is permitted, provided the original author(s) and the copyright owner(s) are credited and that the original publication in this journal is cited, in accordance with accepted academic practice. No use, distribution or reproduction is permitted which does not comply with these terms. 